\title{
PENGARUH VARIASI BENTUK KOMBINASI SHEAR CONNECTOR TERHADAP PERILAKU LENTUR BALOK KOMPOSIT BETON-KAYU
}

\author{
Fengky Satria Yoresta ${ }^{1}$, Muhammad Irsyad Sidiq ${ }^{2}$
}

\begin{abstract}
ABSTRAK
Tulangan besi yang berfungsi menahan beban tarik yang diterima oleh balok beton digantikan oleh kayu menjadi balok komposit beton-kayu. Penelitian ini bertujuan menentukan nilai MOE dan MOR balok komposit beton-kayu dan pengaruh variasi bentuk kombinasi penghubung geser (shear connector) terhadap perilaku lentur balok komposit beton-kayu. Balok komposit dalam penelitian ini menggunakan dua tipe bentuk kayu perkuatan dan tiga tipe bentuk shear connector. Beton dicor dengan perbandingan 1:2:3 (semen : pasir : kerikil). Kayu perkuatan yang dipakai adalah jenis kayu kamper (Dryobalanops sp). Balok komposit beton-kayu diuji dengan metode one point loading dengan dimensi 60x120x900 $\mathrm{mm}^{3}$. Balok komposit beton-kayu yang menggunakan cekukan memiliki kekuatan yang lebih tinggi daripada balok komposit beton-kayu yang rata. Nilai MOE dan MOR terbesar terdapat pada sampel uji B2K2. Sedangkan MOE dan MOR terendah terdapat pada sampel uji B1K1. Nilai MOR beton bertulang berada dibawah MOR semua sampel uji, namun nilai MOE nya lebih besar dari balok tipe 1 dan lebih rendah dari balok tipe 2 .
\end{abstract}

Kata kunci : balok komposit, beton, kayu, shear connector

\section{PENDAhUluan}

Pada prinsipnya suatu bangunan struktural memperhitungkan tiga unsur penting yaitu kekakuan (stiffness), kekuatan (strength), dan kestabilan (stability) struktur (Sadiyo 2011). Salah satu material yang sering digunakan yaitu beton. Beton banyak digunakan pada bangunan bertingkat sebagai balok, kolom, dan pondasi (Julianto 2013). Sifat utama beton adalah sangat kuat menahan beban tekan tetapi lemah dalam menahan beban tarik. Bahkan Wikana (2007) menyatakan kekuatan tarik beton sangat kecil hanya sekitar $10 \%$ dari kuat tekannya. Ketika mendapatkan beban lentur, penampang balok akan mengalami tekan dan tarik di saat yang bersamaan. Pada umumnya digunakan tulangan baja pada balok beton untuk menopang beban tarik yang diterima balok sekaligus untuk mencegah terjadinya retak.

Di sisi lain kayu merupakan bahan material yang didapatkan alami dari pohon. Kayu Kamper (Dryobalanops sp), adalah kayu yang tergolong kedalam kelas kuat I dan II. Kayu ini memiliki kekuatan yang tinggi, sehingga berpotensi untuk digunakan sebagai perkuatan pada balok beton menggantikan baja tulangan.

Dalam pembuatannya, digunakan penghubung geser untuk mengikat antara beton dan kayu (shear connector) pada balok beton-kayu. Selain sebagai pengikat antara beton dan kayu shear connector

${ }^{1}$ Staff Pengajar Institut Pertanian Bogor, Kampus IPB Dramaga Bogor 16001, syfengky@gmail.com

${ }^{2}$ Mahasiswa Sarjana Institut Pertanian Bogor, Kampus IPB Dramaga Bogor 16001 
ini memiliki fungsi utama sebagai penahan geser yang terjadi pada balok. Dimana pada sumbu netral balok adalah bagian yang menerima geser akibat tegangan pada bagian tekan dan tarik. Dalam penelitian ini menggunakan beberapa variasi bentuk shear connector yang digunakan untuk mengetahui kekuatan yang diberikan pada balok komposit beton-kayu.

Penelitian ini bertujuan menentukan nilai MOE dan MOR balok komposit beton-kayu dan perilaku lentur balok komposit beton-kayu yang menggunakan berbagai variasi bentuk shear connector. Hasil penelitian ini kemudian dibandingkan dengan balok kontrol yang terbuat dari beton bertulang.

\section{METODE PENELITIAN}

Campuran beton yang digunakan memiliki perbandingan 1:2:3 (semen:pasir:kerikil) dengan kuat tekan rencana $\pm 150 \mathrm{~kg} / \mathrm{cm}^{2}$ (Boen 2000a). Kayu kamper yang digunakan berasal dari Banjarmasin, Kalimantan Selatan. Sementara shear connector terbuat pelat besi dengan ketebalan $2 \mathrm{~mm}$ yang dibentuk menjadi beberapa variasi dengan sekrup sebagai pengaku. Pengujian lentur terhadap semua balok dilakukan menggunakan Universal Testing Machine (UTM) Baldwin kapasitas 30 ton.

Kayu kamper terlebih dahulu dipotong dan dibentuk menurut dimensi seperti yang diperlihatkan pada Gambar 2.1. Shear connector yang telah dilubangi ditempatkan pada setiap jarak $20 \mathrm{~cm}$ seperti yang diperlihatkan pada Gambar 2.2 menggunakan sekrup. Shear connector yang digunakan terdiri atas tiga variasi bentuk dan dimensi seperti pada Gambar 2.3. Kayu kamper yang telah terpasang shear connector ditempatkan kedalam cetakan (Gambar 2.4). Balok kontrol menggunakan empat buah tulangan utama berdiameter $8 \mathrm{~mm}(\varnothing 8 \mathrm{~mm})$. Sedangkan tulangan sengkang berdiameter $6 \mathrm{~mm}(\varnothing 6 \mathrm{~mm})$ ditempatkan pada setiap jarak $200 \mathrm{~mm}$ (Gambar 2.5). Dimensi balok komposit dan balok kontrol masing-masing adalah $60 \mathrm{~mm}$ x $120 \mathrm{~mm}$.

Campuran beton dituangkan ke dalam cetakan yang telah ditempatkan kayu kamper di bawahnya. Beton kemudian dikondisikan selama minimal 28 hari untuk mencapai kuat tekan rencana. Sebelum diuji lentur, kayu perkuatan tersebut diukur kadar airnya menggunakan moisture meter. Pengujian lentur balok komposit beton-kayu dilakukan menggunakan UTM Baldwin dalam keadaan kadar air kayu sekitar $9-12 \%$. Pengujian lentur dilakukan dengan metode one point loading dengan jarak tumpuan $90 \mathrm{~cm}$. Total semua sampel uji balok berjumlah 18 buah ditambah 1 balok kontrol seperti diperlihatkan pada Tabel 2.1.

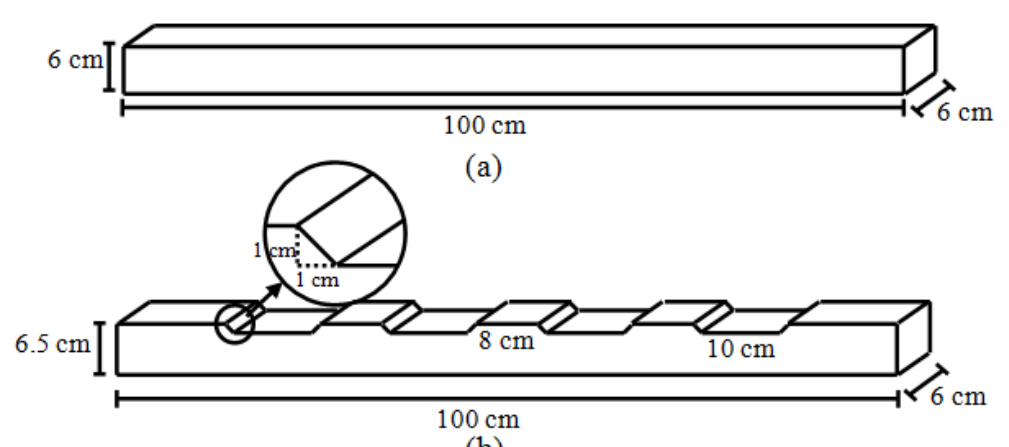

(b)

Gambar 2.1 Dimensi kayu perkuatan yang digunakan pada balok komposit:

(a) tipe 1 (b) tipe 2

26 I JURNAL REKAYASA SIPIL 


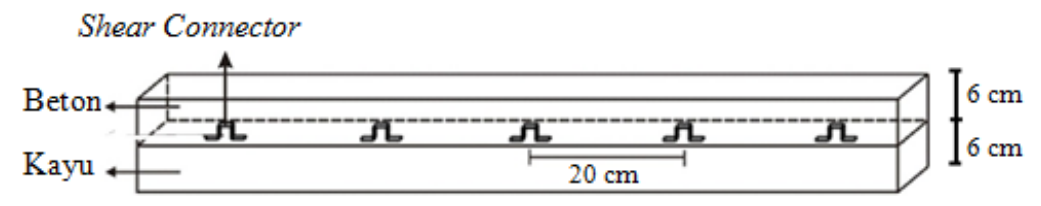

(a)

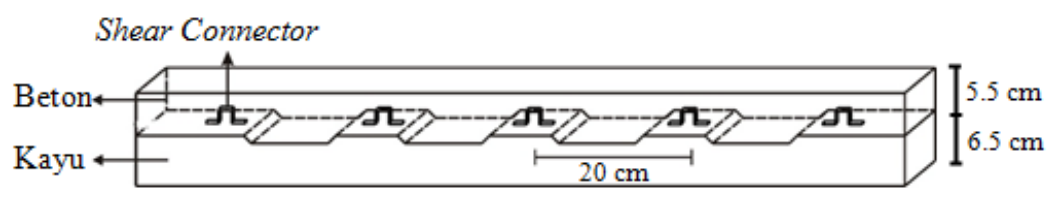

(b)

Gambar 2.2 Sketsa sampel uji: (a) balok tipe 1, (b) balok tipe 2

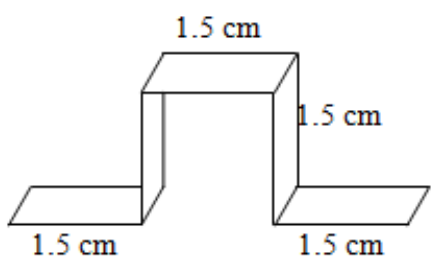

(a)

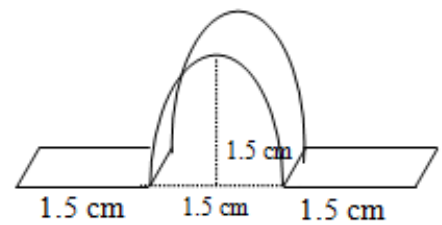

(b)

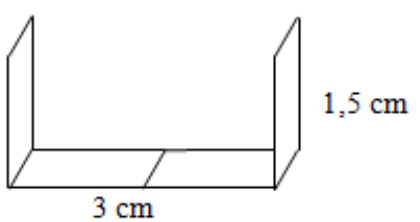

(c)

Gambar 2.3 Bentuk dan ukuran shear connector: (a) tipe 1, (b) tipe 2, dan (c) tipe 3

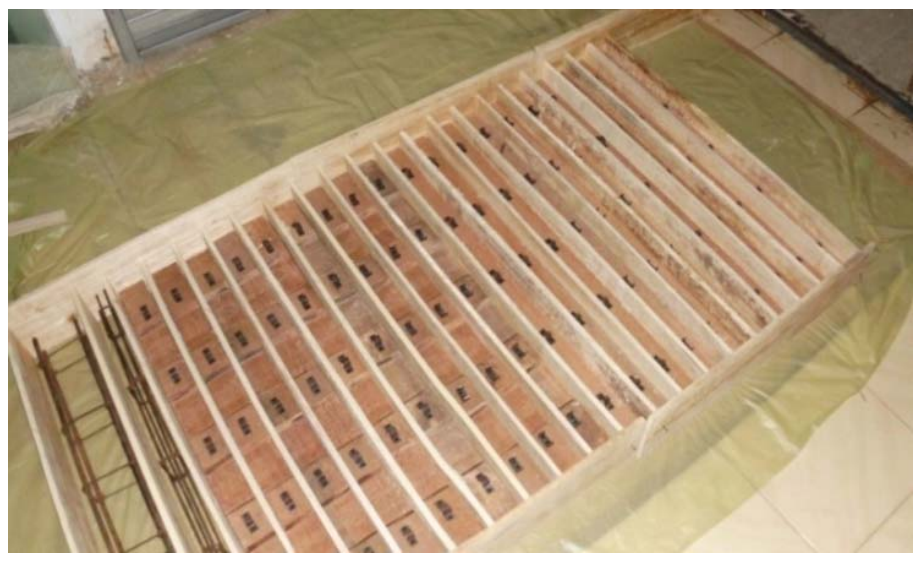

Gambar 2.4 Cetakan Sampel Uji 


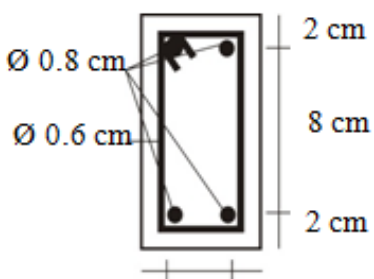

$1 \mathrm{~cm} 4 \mathrm{~cm} 1 \mathrm{~cm}$

(a)

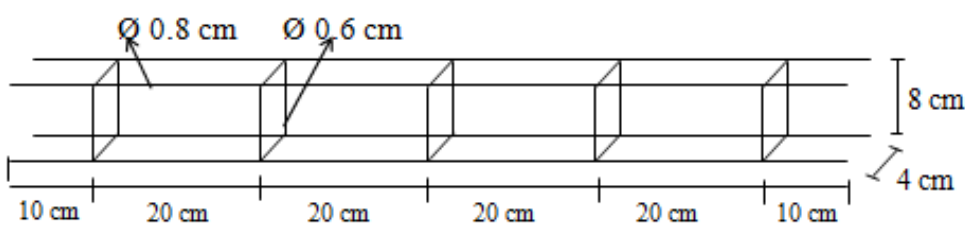

(b)

Gambar 2.5 Balok kontrol: (a) penampang balok, (b) sketsa tulangan

Tabel 2.1 Penamaan Sampel Uji

\begin{tabular}{|c|c|c|}
\hline Balok & Konektor & Nama Sampel Uji \\
\hline \multirow{9}{*}{ Tipe 1} & \multirow{3}{*}{ Tipe 1} & B1K1U1 \\
\hline & & B1K1U2 \\
\hline & & B1K1U3 \\
\hline & \multirow{3}{*}{ Tipe 2} & B1K2U1 \\
\hline & & B1K2U2 \\
\hline & & B1K2U3 \\
\hline & \multirow{3}{*}{ Tipe 3} & B1K3U1 \\
\hline & & B1K3U2 \\
\hline & & B1K3U3 \\
\hline \multirow{9}{*}{ Tipe 2} & \multirow{3}{*}{ Tipe 1} & B2K1U1 \\
\hline & & B2K1U2 \\
\hline & & B2K1U3 \\
\hline & \multirow{3}{*}{ Tipe2 } & B2K2U1 \\
\hline & & B2K2U2 \\
\hline & & B2K2U3 \\
\hline & \multirow{3}{*}{ Tipe 3} & B2K3U1 \\
\hline & & B2K3U2 \\
\hline & & B2K3U3 \\
\hline Beton Bertulang & & Kontrol \\
\hline
\end{tabular}

\section{HASIL DAN PEMBAHASAN}

\subsection{Analisis Beban dan Defleksi}

Gambar 3.1 menunjukkan bahwa sampel uji B2K1 memiliki kekakuan dan kekakuan yang lebih tinggi. Hal ini ditunjukkan dari grafik yang memiliki kemiringan tinggi dan nilai y yang tinggi. Hal ini disebabkan karena pada tipe balok 2 memiliki cekukan dan menggunakan shear connector yang berfungsi sebagai penahan geser, sehingga mampu menerima tegangan yang lebih tinggi daripada tipe balok 1 dan balok kontrol. Pada balok kontrol digunakan tulangan utama sebagai penahan tarik dan tulangan sengkang sebagai penahan geser (Basuki 2006). Pada tipe balok 1 hanya menggunakan shear connector sebagai penahan geser sekaligus sebagai pengikat antar beton dan kayu yang menyebabkan tipe balok 1 tidak memiliki kekakuan yang lebih tinggi daripada balok kontrol. Namun tipe balok 1 memiliki keuntungan yaitu bersifat daktail, hal ini terlihat dari grafik karena mampu menahan lendutan yang tinggi dan tidak mudah runtuh. Biasanya balok yang bersifat daktail dimanfaatkan untuk bangunan agar mampu menahan gempa (SNI 2002). 


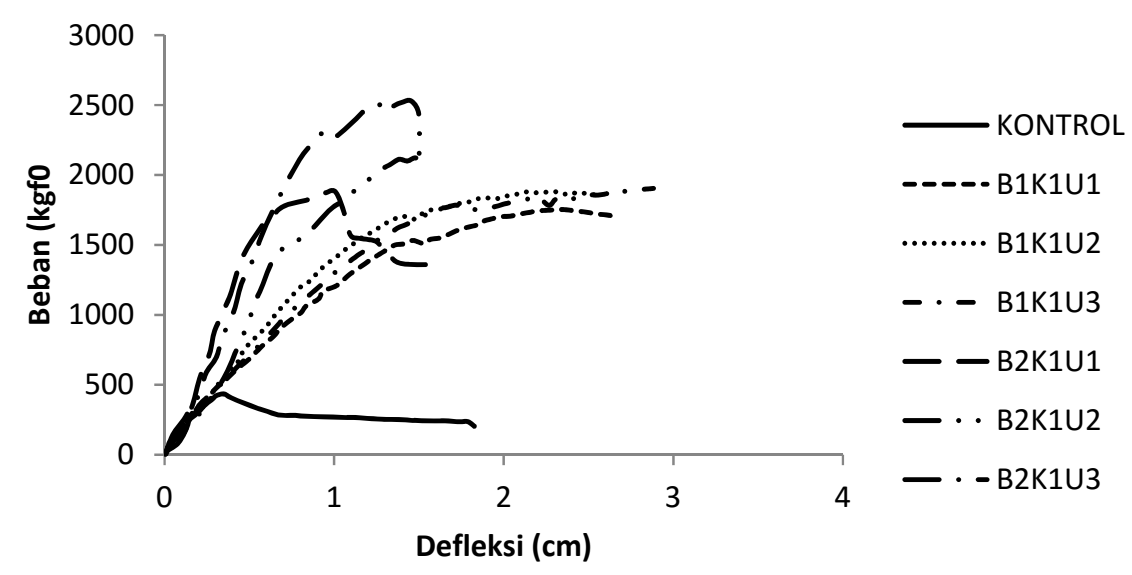

Gambar 3.1 Perbandingan kekuatan balok yang menggunakan shear connector tipe 1

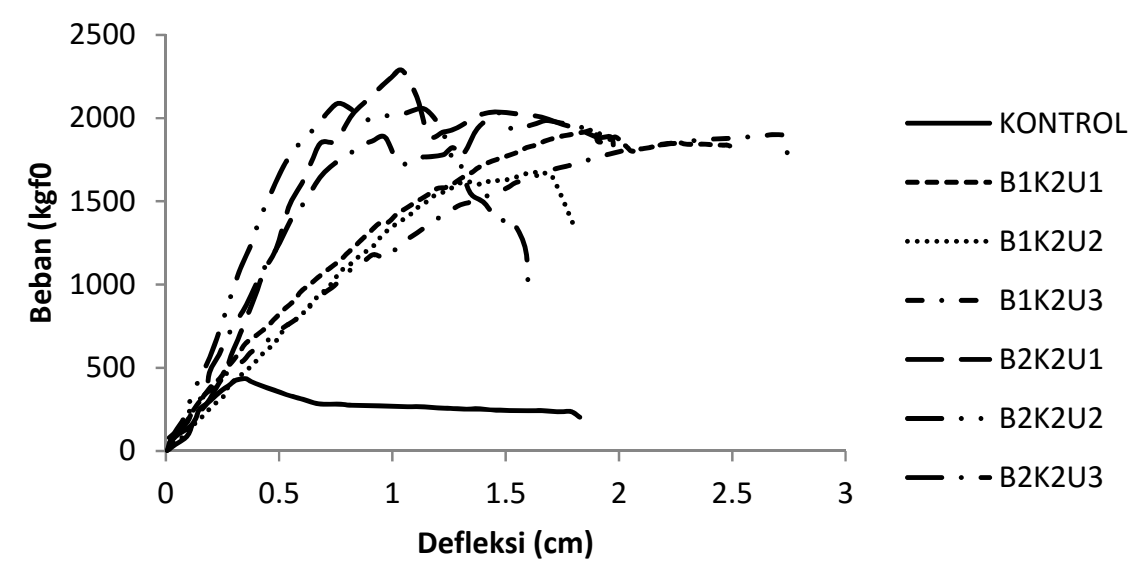

Gambar 3.2 Perbandingan kekuatan balok yang menggunakan shear connector tipe 2

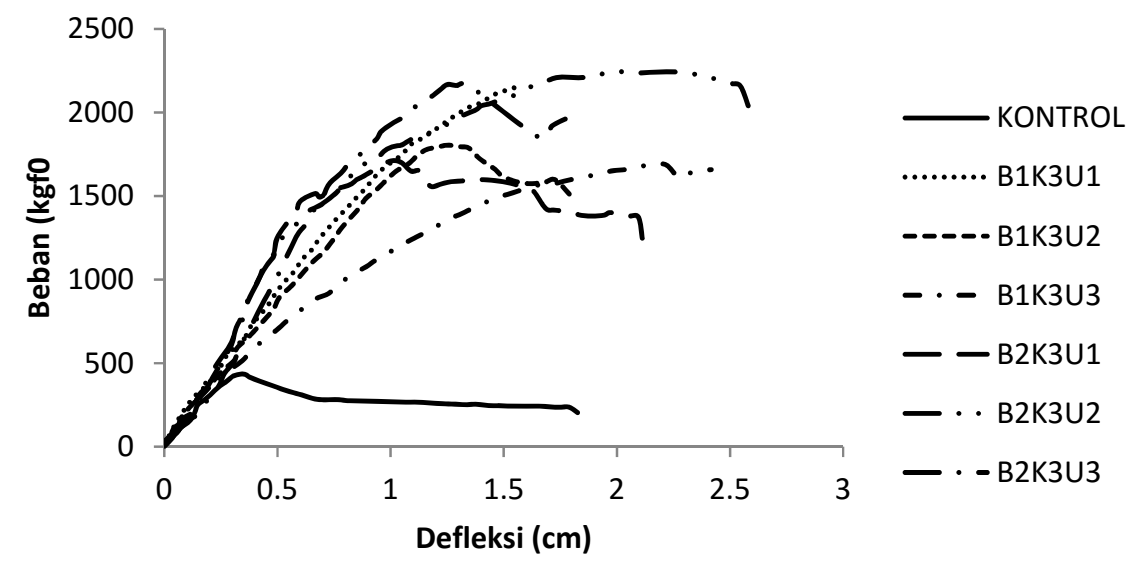

Gambar 3.3 Perbandingan kekuatan balok yang menggunakan shear connector tipe 3 
Gambar 3.2 menunjukkan bahwa pada balok komposit yang menggunakan tipe konektor 2, tipe balok 2 juga yang memiliki kekakuan dan kekakuan yang lebih tinggi. Hal ini ditunjukkan dari grafik yang memiliki kemiringan tinggi dan nilai y yang tinggi. Hal ini disebabkan karena pada tipe balok 2 memiliki cekukan dan menggunakan shear connector yang berfungsi sebagai penahan geser, sehingga mampu menerima tegangan yang lebih tinggi daripada tipe balok 1 dan balok kontrol.

Gambar 3.3 semakin memperkuat bahwa dengan menggunakan tipe tipe balok 2, balok komposit beton-kayu memiliki kekakuan dan kekakuan yang lebih tinggi. Hal ini ditunjukkan dari grafik yang memiliki kemiringan tinggi dan nilai y yang tinggi. Dan tipe balok 1 lebih bersifat daktail dibandingkan dengan tipe balok 2 dan kontrol.

\subsection{Modulus of Elasticity (MOE) dan Modulus of Rupture (MOR)}

Pengujian lentur mendapatkan nilai $\mathrm{P}_{\max }$, MOE, dan MOR seperti yang disajikan pada Tabel 3.1. Nilai $\mathrm{P}_{\max }$ adalah beban maksimal yang mampu ditahan oleh balok. MOE menggambarkan kekakuan balok, sedangkan MOR merupakan nilai kekuatan lentur balok. Berdasarkan Tabel 3.1, hasil penelitian menunjukkan bahwa nilai MOE dan MOR tertinggi terdapat pada sampel uji B2K2. Sedangkan MOE dan MOR yang terendah terdapat pada sampel uji B1K1. Sampel uji B1K3 memiliki MOE mendekati balok kontrol. Perbandingan nilai rata-rata kekakuan, $\mathrm{P}_{\max }, \mathrm{MOE}$, dan MOR balok beton-kayu dan balok kontrol disajikan pada Tabel 3.2.

$\underline{\text { Tabel 3.1 Hasil pengujian lentur balok komposit beton-kayu. }}$

\begin{tabular}{ccccc}
\hline Sampel Uji & $\begin{array}{c}\text { Kekakuan } \\
(\mathrm{kgf} / \mathrm{cm})\end{array}$ & $\mathrm{P}_{\max }(\mathrm{kgf})$ & $\mathrm{MOE}\left(\mathrm{kgf} / \mathrm{cm}^{2}\right)$ & $\mathrm{MOR}\left(\mathrm{kgf} / \mathrm{cm}^{3}\right)$ \\
\hline B1K1U1 & 1104 & 1753 & 15418.76 & 225.18 \\
B1K1U2 & 1431 & 1879 & 22181.54 & 267.53 \\
B1K1U3 & 1153 & 1904 & 16647.23 & 247.07 \\
Rata-rata & 1229 & 1845 & 18082.51 & 246.59 \\
\hline B1K2U1 & 1274 & 1927 & 19435.26 & 264.93 \\
B1K2U2 & 1321 & 1675 & 19593.68 & 224.52 \\
B1K2U3 & 1191 & 1900 & 17684.01 & 253.20 \\
Rata-rata & 1262 & 1834 & 18904.32 & 247.55 \\
\hline B1K3U1 & 1688 & 2161 & 24773.97 & 286.23 \\
B1K3U2 & 1588 & 1804 & 23855.92 & 247.59 \\
B1K3U3 & 968 & 1690 & 14108.55 & 224.98 \\
Rata-rata & 1415 & 1885 & 20912.81 & 252.93 \\
\hline B2K1U1 & 3303 & 1882 & 45412.33 & 233.83 \\
B2K1U2 & 2564 & 2121 & 37116.24 & 277.47 \\
B2K1U3 & 2729 & 2529 & 37556.90 & 313.24 \\
Rata-rata & 2865 & 2177 & 40028.49 & 274.85 \\
\hline B2K2U1 & 3090 & 2285 & 45716.91 & 303.01 \\
B2K2U2 & 3299 & 2088 & 50167.96 & 286.95 \\
B2K2U3 & 2452 & 1885 & 34024.57 & 240.90 \\
Rata-rata & 2947 & 2086 & 43303.15 & 276.95 \\
\hline B2K3U1 & 2733 & 1711 & 39658.00 & 224.37 \\
B2K3U2 & 2337 & 2245 & 35324.99 & 304.99 \\
B2K3U3 & 2214 & 2170 & 30191.72 & 268.15 \\
Rata-rata & 2428 & 2042 & 35058.24 & 265.84 \\
\hline Kontrol & 1336 & 435 & 21564.92 & 64.13 \\
Kamper (Puspita 2015) & - & - & 25685.36 & 608.18 \\
\hline
\end{tabular}

30 | JURNAL REKAYASA SIPIL 
Tabel 3.2 Perbandingan nilai rata-rata kekakuan, $\mathrm{P}_{\max }$, MOE dan MOR terhadap kontrol

\begin{tabular}{ccccc}
\hline \multirow{2}{*}{ Sampel Uji } & Kekakuan $(\mathrm{kgf} / \mathrm{cm})$ & $\mathrm{P}_{\max }(\mathrm{kgf})$ & $\mathrm{MOE}\left(\mathrm{kgf} / \mathrm{cm}^{2}\right)$ & $\mathrm{MOR}\left(\mathrm{kgf} / \mathrm{cm}^{3}\right)$ \\
\hline B1K1 & $-8 \%$ & $324 \%$ & $-16 \%$ & $284 \%$ \\
B1K2 & $-6 \%$ & $322 \%$ & $-12 \%$ & $286 \%$ \\
B1K3 & $6 \%$ & $333 \%$ & $-3 \%$ & $294 \%$ \\
B2K1 & $114 \%$ & $400 \%$ & $86 \%$ & $329 \%$ \\
B2K2 & $121 \%$ & $380 \%$ & $100 \%$ & $332 \%$ \\
B2K3 & $82 \%$ & $370 \%$ & $63 \%$ & $315 \%$ \\
\hline
\end{tabular}

Balok kontrol memiliki nilai kekakuan yang tinggi. Nilai MOE balok tipe 1 lebih rendah dibandingkan dengan balok kontrol. Sedangkan nilai MOE tipe balok 2 lebih besar $63-100 \%$ dibandingkan dengan balok kontrol. Nilai MOR sampel uji jauh lebih besar daripada MOR balok kontrol. Hal ini mengindikasikan bahwa balok kontrol tidak mampu menahan beban yang sangat besar. Ketika balok kontrol mengalami retak, maka beban yang mampu diterima menjadi berkurang. Semakin besar retaknya maka akan semakin berkurang kekuatannya.

\section{KESIMPULAN}

Perbedaan bentuk shear connector mempengaruhi karakteristik balok komposit beton-kayu. Balok komposit beton-kayu yang menggunakan tipe kayu perkuatan yang memiliki cekukan menunjukkan kekuatan yang lebih tinggi daripada balok komposit beton-kayu yang menggunakan tipe kayu perkuatan yang rata maupun kontrol. Balok yang memiliki nilai MOE dan MOR terbesar adalah B2K2 yaitu sebesar $43303.15 \mathrm{kgf} / \mathrm{cm}^{2}$ dan $276.95 \mathrm{kgf} / \mathrm{cm}^{3}$. Balok yang memiliki nilai MOE dan MOR terendah adalah B1K1 yaitu $18082.51 \mathrm{kgf} / \mathrm{cm}^{2}$ dan $246.59 \mathrm{kgf} / \mathrm{cm}^{3}$. Beton bertulang memiliki nilai MOE dan MOR masing-masing sebesar $21564.92 \mathrm{kgf} / \mathrm{cm}^{2}$ dan $64.13 \mathrm{kgf} / \mathrm{cm}^{3}$.

\section{DAFTAR KEPUSTAKAAN}

Basuki. (2006). Rekayasa tulangan sengkang vertikal pada balok beton bertulang. Jurnal Eco Rekayasa. $2(2): 72-80$.

Boen T. (2000a). Bangunan Rumah Tinggal Sederhana : Belajar dari Kerusakan Akibat Gempa. Prosiding Lokakarya Nasional Bangunan Sederhana Tahan Gempa. UII, Yogyakarta.

Julianto. (2013). Kajian Kuat Lentur Balok Beton Bertulang Biasa dan Balok Beton Bertulang Kayu dan Bambu pada Simpel Beam. [skripsi]. Universitas Muhammadiyah Surakarta.

Puspita L M. (2015). Kapasitas dan Perilaku Lentur Balok Komposit Beton-Kayu. [skripsi]. Fakultas Kehutanan IPB.

Sadiyo S. (2011). Analisis sesaran batas proporsional dan maksimum sambungan geser ganda batang kayu dengan paku majemuk berpelat sisi baja akibat beban uni-aksial tekan. Jurnal Teknik Sipil. 18(2): 127135. doi: ISSN 0853-2962.

Standar Nasional Indonesia [SNI]. (2002). Standar Perencanaan Ketahanan Gempa untuk Struktur Bangunan Gedung SNI - 1726 - 2002. Bandung [ID] : Pusat Penelitian dan Pengembangan Teknologi Pemukiman.

Wikana I. Widayat Y. (2007). Tinjauan kuat lentur balok beton bertulang dengan lapisan mutu beton yang berbeda. Majalah Ilmiah UKRIM. Edisi 2/th XII. 